\title{
Transcriptome sequencing and microarray development for the Manila clam, Ruditapes philippinarum: genomic tools for environmental monitoring
}

\author{
Massimo Milan ${ }^{1,2^{*}}$, Alessandro Coppe ${ }^{3}$, Richard Reinhardt ${ }^{4}$, Leonor M Cancela ${ }^{5}$, Ricardo B Leite ${ }^{5}$, Carlos Saavedra ${ }^{6}$, \\ Claudio Ciofi ${ }^{2}$, Guido Chelazzi ${ }^{2}$, Tomaso Patarnello ${ }^{1}$, Stefania Bortoluzzi ${ }^{3}$ and Luca Bargelloni ${ }^{1}$
}

\begin{abstract}
Background: The Manila clam, Ruditapes philippinarum, is one of the major aquaculture species in the world and a potential sentinel organism for monitoring the status of marine ecosystems. However, genomic resources for $R$. philippinarum are still extremely limited. Global analysis of gene expression profiles is increasingly used to evaluate the biological effects of various environmental stressors on aquatic animals under either artificial conditions or in the wild. Here, we report on the development of a transcriptomic platform for global gene expression profiling in the Manila clam.
\end{abstract}

Results: A normalized cDNA library representing a mixture of adult tissues was sequenced using a ultra highthroughput sequencing technology (Roche 454). A database consisting of 32,606 unique transcripts was constructed, 9,747 (30\%) of which could be annotated by similarity. An oligo-DNA microarray platform was designed and applied to profile gene expression of digestive gland and gills. Functional annotation of differentially expressed genes between different tissues was performed by enrichment analysis. Expression of Natural Antisense Transcripts (NAT) analysis was also performed and bi-directional transcription appears a common phenomenon in the R. philippinarum transcriptome. A preliminary study on clam samples collected in a highly polluted area of the Venice Lagoon demonstrated the applicability of genomic tools to environmental monitoring.

Conclusions: The transcriptomic platform developed for the Manila clam confirmed the high level of reproducibility of current microarray technology. Next-generation sequencing provided a good representation of the clam transcriptome. Despite the known limitations in transcript annotation and sequence coverage for non model species, sufficient information was obtained to identify a large set of genes potentially involved in cellular response to environmental stress.

\section{Background}

The Manila clam Ruditapes philippinarum (Adams \& Reeve, 1850) is a bivalve mollusc of the family Veneridae native to the Indo-Pacific region. Because of its commercial value as seafood, this species has been introduced to other regions, where it has become permanently established. In Europe it was first imported

\footnotetext{
* Correspondence: massimo.milan@unifi.it

'Department of Public Health, Comparative Pathology, and Veterinary Hygiene, Faculty of Veterinary Medicine, University of Padova, Viale dell'Università 16, 35020 Legnaro, Italy

Full list of author information is available at the end of the article
}

in 1972 in France. Additional introductions occurred from Oregon to the United Kingdom, followed by numerous transfers within European waters for aquaculture purposes (Portugal, Ireland, Spain, and Italy). Natural reproduction of introduced individuals favored geographical expansion into the wild, particularly in Italy, France, Spain and Ireland where the Manila clam proved to be more resistant and grew faster than the endemic carpet-shell clam, $R$. decussatus. Consequently, $R$. philippinarum displaced its autochthonous congeneric species in most areas, and now represents the most important species for commercial clam landings in 
Europe. Globally, harvest of $R$. philippinarum has experienced a dramatic increase in the last 20 years, currently representing one of the major aquacultured species in the world (3.36 million metric tons in 2008). China is by far the leading producer $(97.4 \%$ of total annual production) while Italy has a smaller but yet conspicuous production of over 65,000 tonnes per year [1].

Despite the relevance of Manila clam landings in world aquaculture, genomic resources for $R$. philippinarum are still extremely limited [2]. A small set of genetic markers is available [3] and only 5,707 transcripts has been sequenced and are already available on GENBANK. Although $R$. philippinarum is considered a robust species, capable of adapting to a wide range of environments, infectious diseases, chronic parasitic (e.g. Perkinsus -like microorganisms) and bacterial (e.g. brown ring bacterial disease) infections, it has been suffering mass mortality that have caused severe production losses in different areas (European Atlantic waters, Yellow Sea) [1]. The impact of infections is often aggravated under particular environmental conditions, such as extreme temperatures or limited availability of oxygen or nutrients. However, massive mortalities are rarely explained by a single parameter. An understanding of the interactions among different biotic and abiotic factors influencing survival is therefore a high priority for clam aquaculture. Functional genomics, or more specifically physiological genomics, i.e. a global analysis of transcriptome responses to different conditions, offers unprecedented opportunities to achieve such a goal. For instance, a genomic analysis was recently used to investigate summer mortality in the Pacific oyster [4]. To this end, the development of transcriptomic tools for the Manila clam is the first necessary step.

A second and possibly more important application of global gene expression profiling in $R$. philippinarum is environmental monitoring. Genomic technologies are increasingly used to evaluate the biological effects of various chemical pollutants on aquatic animals under either controlled conditions or in natural environments (e.g. $[5,6])$. While several hurdles remain to be overcome, the outlook for eco-toxicogenomics is extremely promising [7]. A sessile, filter-feeding organism living in the seafloor sediment, $R$. philippinarum represents an excellent "sentinel" species to assess the quality of marine environment. Two recent studies correlating different biochemical, cellular, and organismal markers with levels of pollutants in the sediment [8] or accumulated in the animals [9] support this view. However, a limited set of multiple biomarkers is usually employed in most of the studies. Therefore, a transcriptomic approach could provide a much broader analysis of different biological processes allowing for an integrated description of responses to xenobiotics $[5,6]$.
The aim of the present study was to fill the gap in transcriptome sequence data available for the Manila clam and to develop a reliable and informative platform for global gene expression profiling, to be then applied to environmental monitoring. To this end, next-generation sequencing was coupled with a technology, in situ synthesized oligo array, which has provided a robust and flexible microarray platform in other species using conventional Sanger sequencing [10-18].

To date, 454 mollusc data are available only for Mytilus galloprovincialis and Bathymodiolus azoricus [19,20], and to our knowledge, this is the first report of an oligo DNA microarray developed using ultra-high throughput pyrosequencing in a mollusc species. A free web-accessible database including extensive transcript annotation and a blast search option was also developed in support of the gene expression platform.

In order to assess the feasibility of this newly developed R.philippinarum microarray to toxicogenomics, a preliminary investigation has been performed by profiling gene expression in gills and digestive glands of clams sampled in the industrial area of Marghera, a highly polluted site of the Venice Lagoon, compared to animals sampled in a clean area of the lagoon of Venice.

\section{Results and Discussion}

Next-generation sequencing and hybrid contig assembly

Starting from a total of 463,424 sequences (see Methods), a first run of hybrid assembly grouped 191,624 reads (41\%) into 40,477 contigs. The resulting assembled sequences and the remaining singletons were then used as input for a second MIRA run (see methods) of assembly in order to produce meta-contigs from a fraction of partially redundant contigs obtained by the first run. This approach produced a set of 32,606 contigs. Summary statistics of the ESTs generated for $R$. philippinarum and their assembly are reported in Table 1. Figure 1 shows the distribution of sequence length and the relationship between length and average quality for the 32,606 contigs. All Roche 454 FLX reads have been deposited in GenBank (GenBank:SRR058508.1SRR058508.457717).

\section{Transcriptome annotation}

Putative identities of assembled contigs and meta-contigs were obtained by running Blastx and Blastn similarity searches on several protein and nucleotide databases (see Additional file 1). Of 32,606 unique sequences, 7,907 (24\%) showed at least one significant match $(\mathrm{e}<$ 10-5) in the NCBI non-redundant protein database. The use of Blast2GO software allowed the association of one or more GO terms to $6,867 R$. philippinarum data base entries. Of these, 2,788 were linked to "Biological Process" (BP) GO entries, 2,880 to "Cellular Component" 
Table 1 Summary of generated Ruditapes philippinarum ESTs and assembly results with statistics describing different properties of transcriptome contig sequences available in Ruditapes philippinarum Database (compgen. bio.unipd.it/RuphiBase)

\begin{tabular}{llc}
\hline & Feature & Value \\
\hline Sequences & 454 reads & $\mathbf{4 5 7 , 7 1 7}$ \\
& Sanger sequences & $\mathbf{5 , 7 0 7}$ \\
\cline { 2 - 3 } & Assembled sequences & $\mathbf{1 9 1 , 6 2 4}$ \\
\hline Contigs & First run of hybrid assembly & $\mathbf{4 0 , 4 7 7}$ \\
\cline { 2 - 3 } & Meta-contigs of second assembly & $\mathbf{4 , 9 9 0}$ \\
& Not re-assembled & $\mathbf{2 7 , 6 1 6}$ \\
\cline { 2 - 3 } & Total (Ruditapes philippinarum transcriptome) & $\mathbf{3 2 , 6 0 6}$ \\
& Mean length (bp) & $\mathbf{5 4 6}$ \\
& Max length (bp) & $\mathbf{2 4 9 7}$ \\
& Mean Average quality (Phred) & $\mathbf{3 9 . 2}$ \\
& Mean GC\% & $\mathbf{3 3 . 5}$ \\
\hline
\end{tabular}

(CC) entries, and 3,141 to "Molecular Function" (MF) entries. Unique GO terms represented in $R$. philippinarum entries were 1,515 for BP, 380 for CC, and 655 for MF. A simplified view of these GO terms using a "Generic GO Slim" showed 46 BP, $30 \mathrm{CC}$, and 34 MF classes (see Additional File 2).

In addition to the annotation with Blast2GO, Blast searches against UniProtKB/Swiss-Prot database, UniProtKB/TrEMBL database and 26 different species-specific data bases (see Additiona file 1) were implemented in order to further increase the number of putatively annotated $R$. philippinarum contigs (see Methods for details). This approach provided a significant match for additional 1,840 transcripts, which showed no previous correspondence with either the NCBI non-redundant protein or nucleotide database, and brought the final number of clam entries associated with a known protein or transcript to 9,747 (30\%).

\section{RuphiBase, a Ruditapes philippinarum database}

All 32,606 contig sequences as well as different layers of results for data analysis are available through RuphiBase [21], a free web-accessible database implemented using MySQL and Django web framework. RuphiBase is centered on contig sequence and annotation, and can be searched by contig ID and key word match on different textual fields. Moreover, it allows the user to conduct a local BLAST search on the fly against the transcripts database, in order to identify one or more transcripts significantly similar to a given query sequence. Indeed, massive and customizable data retrieval is provided by a browsing system. For each contig, a gene-like entry shows different data and bioinformatic analyses results according to the scheme detailed below:

- Contig information. For each contig, identified by an ID and a preliminary description, the FASTA sequence is given, along with an informative contig description, which is defined by the Blast2GO natural language text mining functionality, applied to BLAST hits description. The best hit is used when a BLAST2GO description is unavailable.

- Assembly. The list of reads belonging to the contig is given together with two FASTA files which include all read sequences, contig with reads and ESTs sequences and ACE format multiple alignment of the contig with reads and ESTs.

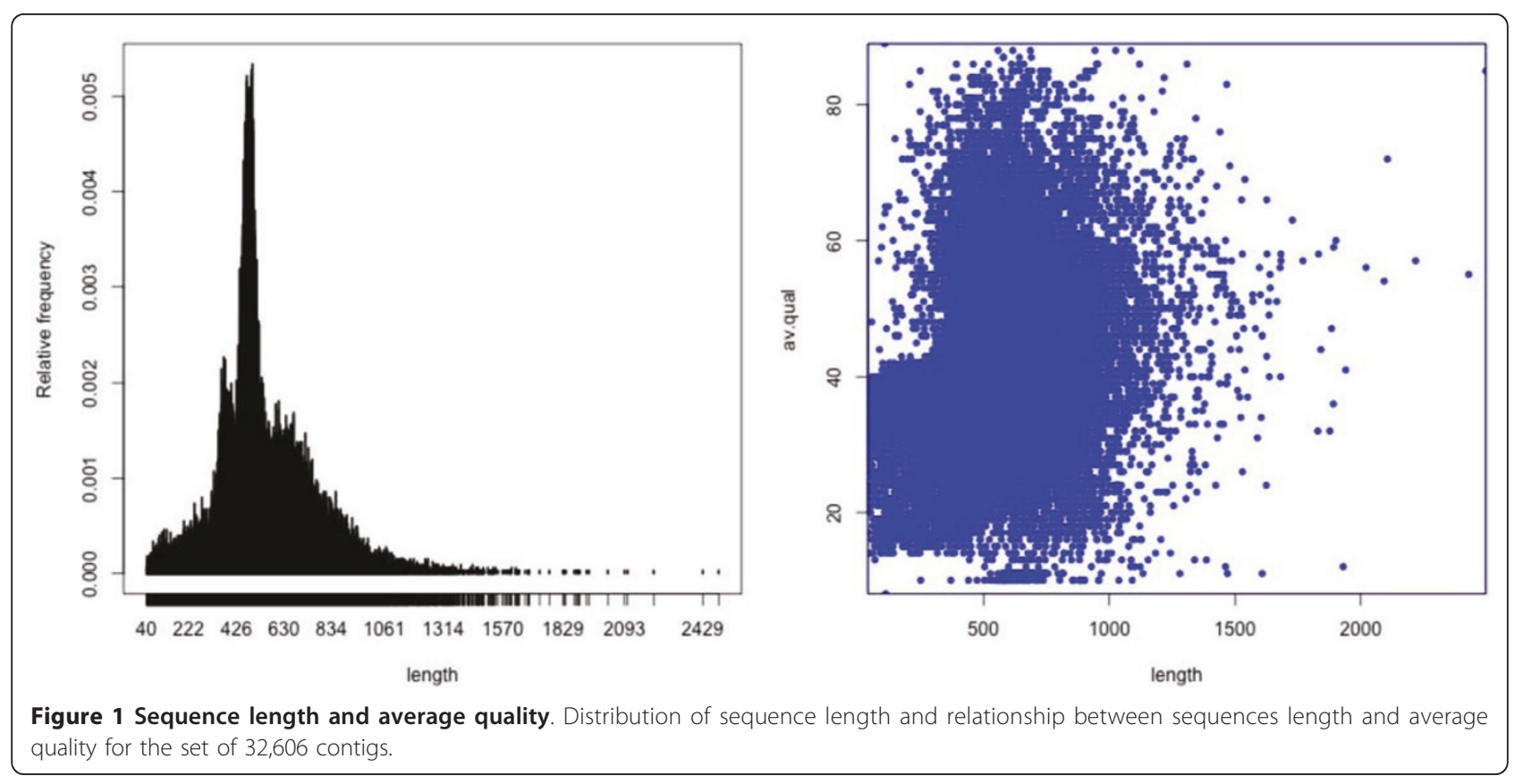


Table 2 Correlation coefficients on the entire set of expression values across biological replicates (**p-value $<0.01)$

\begin{tabular}{lccc}
\hline & Digestive gland Pool 1 & Digestive gland Pool 2 & Digestive gland Pool 3 \\
\hline Digestive gland_Pool 2 & $0.9718101^{* *}$ & & \\
Digestive gland_Pool 3 & $0.9714377^{* *}$ & $0.977098^{* *}$ & $0.981809^{* *}$ \\
Digestive gland_Pool 4 & $0.9665312^{* *}$ & $0.9789406^{* *}$ & \\
\hline
\end{tabular}

- Gene Ontology. GO terms associated to each transcript are given for $\mathrm{BP}, \mathrm{MF}$, and $\mathrm{CC}$, with hyper-link to the GO database.

BLAST results. BLAST results, for both nucleotide and protein database searches, are shown in a dedicated section in the classic BLAST output format. These results are hyperlinked to external databases, and include the list of alignment descriptions and details about the pairwise alignments of each transcript with the corresponding BLAST hits.

\section{Microarray quality assessment}

A total of seven microarray experiments (three biological replicates for gills and four for the digestive gland) were carried out. After data extraction, hybridization success for each probe was inferred if flag "glsFound" values was equal to 1 (see Methods). Across all experiments, only 131 probes $(0.3 \%)$ never showed a signal higher than the background, while 19,360 probes $(46 \%)$ were always successful and 37,379 (88\%) were successful in at least four experiments.

To evaluate the repeatability of the array results, microarray data for the digestive gland (four biological replicates, each replicate consisting of a pool of five individuals) were normalized. The degree of mutual agreement between replicates was assessed by estimating the Pearson correlation coefficients $(r)$ on the entire set

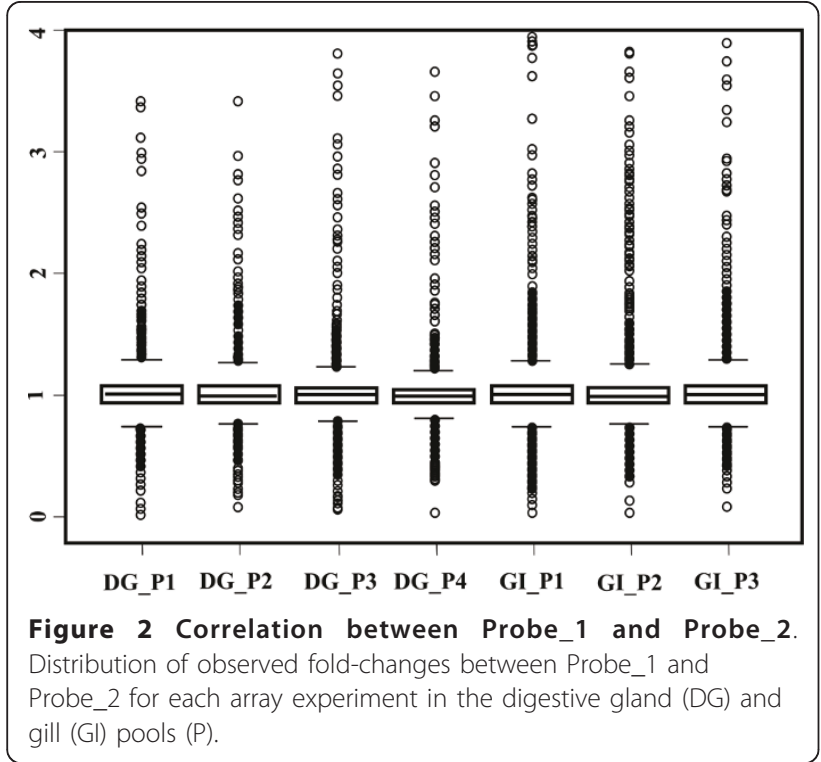

of expression values. Pairwise comparisons of replicate experiments showed correlation coefficients with $\mathrm{r}>$ 0.99 and were always significant ( $\mathrm{p}$-value $<0.01$ ) (see Table 2), confirming a good reproducibility of the microarray platform. Normalized fluorescence data for these comparisons have been deposited in the GEO database [22] under accession numbers GEO:GSE24050. The Manila clam microarray platform is characterized also by the presence of two duplicated probes, at different coordinates on the same array, for a total of 2,000 annotated transcripts. The variability between two identical probes for the same transcript was evaluated using the ratio between the two probe intensity levels (foldchange, FC) as a measure of signal difference. This ratio is expected to assume a value around 1. In Figure 2 each box plot describes the distribution of observed fold-changes between Probe_1 and Probe_2 for each array experiment in the digestive gland and gills pools. This is symmetrical, centered around 1 and equal across all the experiments. Concordance of hybridization signal for probe pairs was confirmed by estimating Pearson correlation coefficients between Probe_1 and Probe_2 for each gene across seven experiments. The correlation coefficient was always greater than 0.95 and highly significant ( $<<0.0001)$ (data not shown).

\section{Comparison of gene expression in the digestive gland and gills}

Fluorescence data microarray experiments of three biological replicates consisting of pooled digestive glands and three pools of gills sampled in Alberoni, a clean area in the Venice Lagoon, were normalized and used to identify genes that were differentially expressed in different tissues.

Digestive glands and gills were chosen because of their relevant role on detoxification of xenobiotics as well as filtration of suspended matter and as defense barrier, respectively. These are cellular/organismal processes crucial in the response to chemical pollutants and/or pathogens exposure. Processed data were deposited in the GEO database [22] under accession number GSE24101. A two-unpaired class Significance Analysis of Microarray (SAM) test was carried out on normalized data, enforcing a False Discovery Rate (FDR) of 3\%. A list of 10,159 significant probes, corresponding to 8,512 unique transcripts, was obtained. A total of 2,880 transcripts were up-regulated in pooled samples of digestive 
gland compared to gills with a $\mathrm{FC}$ ranging from 3 to 23,550 , while a total of 7,279 transcripts was up-regulated in the gills compared to the digestive gland with a FC ranging from 3 to 18,200 . A putative annotation could be obtained for 3,491 genes that were differentially expressed in the two tissues (see Additional file 3). A more systematic functional interpretation of the set of differentially expressed genes was obtained by an enrichment analysis using the Database for Annotation, Visualization, and Integrated Discovery (DAVID) software
[23] with two alternative strategies. In the first case, $R$. philippinarum entries were matched to human Ensembl Gene IDs, while in the second strategy $R$. philippinarum entries were associated with zebrafish Ensembl Gene IDs (see Methods). Human or zebrafish IDs corresponding to differentially expressed Manila clam transcripts and to all genes represented on the array were then used to define a "gene list" and a "background" in DAVID, respectively. This allows functional annotation of differentially expressed genes through enrichment

Table 3 GO terms significantly represented among up-regulated genes in digestive gland compared to gills tissue

\begin{tabular}{|c|c|c|c|c|}
\hline & Term & Count & p-value & F.E. \\
\hline \multirow[t]{4}{*}{ KP } & dre00982:Drug metabolism & 8 & $3.9 \mathrm{E}-05$ & 5.9 \\
\hline & dre00980:Metabolism of xenobiotics by cytochrome P450 & 8 & $3.9 \mathrm{E}-05$ & 5.9 \\
\hline & dre00480:Glutathione metabolism & 9 & $8.8 \mathrm{E}-04$ & 3.7 \\
\hline & dre04142:Lysosome & 14 & $1.9 \mathrm{E}-03$ & 2.4 \\
\hline \multirow[t]{17}{*}{ BP } & GO:0055114 oxidation reduction & 39 & $6.4 \mathrm{E}-06$ & 2.0 \\
\hline & GO:0048468 cell development & 15 & $6.7 \mathrm{E}-06$ & 3.6 \\
\hline & GO:0040008 regulation of growth & 11 & $7.2 \mathrm{E}-06$ & 4.7 \\
\hline & GO:0001558 regulation of cell growth & 10 & $3.2 \mathrm{E}-05$ & 4.6 \\
\hline & GO:0009308 amine metabolic process & 17 & $4.2 \mathrm{E}-05$ & 2.9 \\
\hline & GO:0022008 neurogenesis & 14 & $4.2 \mathrm{E}-05$ & 3.3 \\
\hline & GO:0030182 neuron differentiation & 12 & 4.6E-05 & 3.8 \\
\hline & GO:0048699 generation of neurons & 13 & $8.2 \mathrm{E}-05$ & 3.4 \\
\hline & GO:0016052 carbohydrate catabolic process & 13 & $2.3 \mathrm{E}-04$ & 3.1 \\
\hline & GO:0030154 cell differentiation & 22 & 2.3E-04 & 2.2 \\
\hline & GO:0048869 cellular developmental process & 22 & $8.4 \mathrm{E}-04$ & 2.1 \\
\hline & GO:0005975 carbohydrate metabolic process & 18 & $2.2 \mathrm{E}-03$ & 2.1 \\
\hline & GO:0007399 nervous system development & 14 & $2.5 \mathrm{E}-03$ & 2.4 \\
\hline & GO:0006066 alcohol metabolic process & 13 & 7.7E-03 & 2.2 \\
\hline & GO:0009653 anatomical structure morphogenesis & 20 & $1.1 \mathrm{E}-02$ & 1.8 \\
\hline & GO:0006508 proteolysis & 29 & $1.2 \mathrm{E}-02$ & 1.5 \\
\hline & GO:0006629 lipid metabolic process & 12 & $1.3 \mathrm{E}-02$ & 2.2 \\
\hline \multirow[t]{5}{*}{$\mathrm{CC}$} & GO:0005576 extracellular region & 20 & $1.13 E-05$ & 2.88 \\
\hline & GO:0016021 integral to membrane & 40 & $2.11 E-05$ & 1.85 \\
\hline & GO:0031224 intrinsic to membrane & 40 & 2.44E-05 & 1.84 \\
\hline & GO:0016020 membrane & 55 & $3.34 \mathrm{E}-05$ & 1.57 \\
\hline & GO:0044425 membrane part & 42 & 0.001042 & 1.54 \\
\hline \multirow[t]{12}{*}{ MF } & GO:0030246 carbohydrate binding & 29 & $2.55 E-15$ & 4.56 \\
\hline & GO:0005529 sugar binding & 21 & $2.06 \mathrm{E}-11$ & 4.69 \\
\hline & GO:0003824 catalytic activity & 142 & $4.26 \mathrm{E}-06$ & 1.29 \\
\hline & GO:0016491 oxidoreductase activity & 46 & 1.69E-05 & 1.81 \\
\hline & GO:0005509 calcium ion binding & 27 & $5.43 \mathrm{E}-05$ & 2.18 \\
\hline & GO:0008233 peptidase activity & 30 & $5.02 \mathrm{E}-04$ & 1.85 \\
\hline & GO:0070011 peptidase activity, acting on L-amino acid peptides & 29 & $5.42 \mathrm{E}-04$ & 1.87 \\
\hline & GO:0004175 endopeptidase activity & 25 & 5.63E-04 & 1.99 \\
\hline & GO:0004197 cysteine-type endopeptidase activity & 11 & 1.10E-03 & 3.04 \\
\hline & GO:0016787 hydrolase activity & 59 & 2.99E-03 & 1.39 \\
\hline & GO:0008234 cysteine-type peptidase activity & 11 & $3.79 E-03$ & 2.66 \\
\hline & GO:0004872 receptor activity & 18 & 3.97E-03 & 2.01 \\
\hline
\end{tabular}

Here are the Biological Process (BP), Cellular Component (CC) and Molecular Function (MF) represented by at least 10 genes. Significantly represented KEGG pathways (KP) are also reported. Gene count, p-value and fold enrichment (F.E.) corresponding to each term are indicated. 
Table 4 Biological Process (BP), Cellular Component (CC), KEGG pathways (KP) and Molecular Function (MF) significantly represented by at least $\mathbf{1 0}$ genes up-regulated in gills compared to digestive gland

\begin{tabular}{|c|c|c|c|c|}
\hline & Term & Count & $\mathrm{p}$-value & F.E. \\
\hline \multirow[t]{9}{*}{ KP } & dre04510:Focal adhesion & 20 & 1.05E-04 & 2.31 \\
\hline & dre04540:Gap junction & 8 & $6.50 \mathrm{E}-03$ & 2.93 \\
\hline & dre04310:Wnt signaling pathway & 13 & $1.22 \mathrm{E}-02$ & 2.02 \\
\hline & dre04210:Apoptosis & 8 & $1.24 \mathrm{E}-02$ & 2.69 \\
\hline & dre04114:Oocyte meiosis & 9 & $1.48 \mathrm{E}-02$ & 2.42 \\
\hline & dre04621:NOD-like receptor signaling pathway & 7 & 3.09E-02 & 2.57 \\
\hline & dre04630:Jak-STAT signaling pathway & 5 & 3.50E-02 & 3.36 \\
\hline & dre04622:RIG-I-like receptor signaling pathway & 6 & 4.50E-02 & 2.69 \\
\hline & dre04620:Toll-like receptor signaling pathway & 7 & 4.94E-02 & 2.35 \\
\hline \multirow[t]{19}{*}{ BP } & GO:0050794 regulation of cellular process & 89 & 2.74E-04 & 1.35 \\
\hline & GO:0034622 cellular macromolecular complex assembly & 16 & 3.69E-04 & 2.41 \\
\hline & GO:0065007 biological regulation & 101 & 3.75E-04 & 1.31 \\
\hline & GO:0050789 regulation of biological process & 91 & $8.68 \mathrm{E}-04$ & 1.31 \\
\hline & GO:0007166 cell surface receptor linked signal transduction & 22 & $1.16 \mathrm{E}-03$ & 1.93 \\
\hline & GO:0034621 cellular macromolecular complex subunit organization & 16 & 1.87E-03 & 2.15 \\
\hline & GO:0007017 microtubule-based process & 11 & $2.48 \mathrm{E}-03$ & 2.59 \\
\hline & GO:0022607 cellular component assembly & 20 & 4.27E-03 & 1.84 \\
\hline & GO:0050896 response to stimulus & 39 & $5.63 \mathrm{E}-03$ & 1.47 \\
\hline & GO:0042981 regulation of apoptosis & 10 & $6.07 \mathrm{E}-03$ & 2.51 \\
\hline & GO:0065003 macromolecular complex assembly & 16 & $6.68 \mathrm{E}-03$ & 1.94 \\
\hline & GO:0032501 multicellular organismal process & 60 & 7.63E-03 & 1.32 \\
\hline & GO:0009653 anatomical structure morphogenesis & 28 & 9.94E-03 & 1.55 \\
\hline & GO:0042592 homeostatic process & 17 & $1.01 \mathrm{E}-02$ & 1.83 \\
\hline & GO:0001568 blood vessel development & 10 & 1.07E-02 & 2.35 \\
\hline & GO:0043067 regulation of programmed cell death & 10 & 1.07E-02 & 2.35 \\
\hline & GO:0010941 regulation of cell death & 10 & 1.07E-02 & 2.35 \\
\hline & GO:0001944 vasculature development & 10 & 1.07E-02 & 2.35 \\
\hline & GO:0044085 cellular component biogenesis & 23 & 1.39E-02 & 1.60 \\
\hline \multirow[t]{3}{*}{ CC } & GO:0015630 microtubule cytoskeleton & 11 & 0.005 & 2.423 \\
\hline & GO:0044430 cytoskeletal part & 14 & 0.033 & 1.747 \\
\hline & GO:0005856 cytoskeleton & 22 & 0.044 & 1.471 \\
\hline \multirow[t]{6}{*}{ MF } & GO:0003924 GTPase activity & 11 & $5.20 \mathrm{E}-04$ & 2.97 \\
\hline & GO:0005515 protein binding & 85 & 3.75E-03 & 1.28 \\
\hline & GO:0003700 transcription factor activity & 12 & 5.89E-03 & 2.26 \\
\hline & GO:0019001 guanyl nucleotide binding & 22 & $6.17 \mathrm{E}-03$ & 1.73 \\
\hline & GO:0005525 GTP binding & 22 & $6.17 \mathrm{E}-03$ & 1.73 \\
\hline & GO:0032561 guanyl ribonucleotide binding & 22 & $6.17 \mathrm{E}-03$ & 1.73 \\
\hline
\end{tabular}

Gene count, p-value and fold enrichment (F.E.) corresponding to each term are indicated.

analyses based on an integrated biological knowledgebase, containing over 40 annotation categories. The second strategy allowed the assignment of a putative homologue to a larger number of clam transcripts. In total, 406 genes up-regulated in the digestive gland and 660 genes up-regulated in the gills found a corresponding functional annotation in DAVID. Enrichment analysis for up-regulated transcripts in the digestive gland showed 5 KEGG (Kyoto Encyclopedia of Genes and Genomes) pathways, 20 Biological Process (BP) terms, 5 Cellular Component (CC) terms, and 16
Molecular Function (MF) terms to be significantly over-represented (see Table 3). Enriched gene sets were involved in typical liver and pancreas metabolic processes such as cytochrome P450-mediated metabolism of xenobiotics, retinol metabolism and glutathione metabolism. The digestive gland of molluscs is also called "hepatopancreas" and integrates functions that are liver- and pancreas-specific in vertebrates. A notch signaling pathway was found among enriched KEGG pathways, although with a low statistical significance value $(P=0.09)$. This pathway has a role in timely cell 
lineage specification of both endocrine and exocrine pancreas.

Enrichment analysis on genes that were up-regulated in gills showed 10 KEGG pathway terms, 36 BP-GO terms, 35 CC-GO terms and 11 MF-GO terms, all significantly over-represented (see table 4). Genes over-expressed in the gills were involved in different cellular functions, including cell proliferation, differentiation, and migration. Two signaling pathways, Wnt and JAK-STAT, appeared to be significantly over-represented. The Wnt signaling pathway, with 13 genes over-expressed in gills, describes a complex network of proteins with a broad role in embryogenesis as well as in several cell processes of adult animals. The JAK-STAT signaling pathway transduces information from various chemical signals outside the cell to transcriptional regulation and it is involved in a wide array of cell activities. Other significant pathways, RIG-I-like receptor, NOD-like receptor, and Toll-like receptor signaling suggest a relevant role of immune response for the gills. This is supported by the large amount of hemocytes present in the gills and the presence of lectins and lysozyme among differentially expressed genes (data not shown). Enrichment in genes involved in blood vessel and vascular development is expected in a highly vascularized tissue as the gills, while over-representation of microtubule-associated proteins might reflect the importance of cytoskeletal structures in gill epithelia.

\section{Strand orientation and antisense transcripts}

As already mentioned, a great majority of probes showed a higher-than-background signal in four or more experiments, and nearly all of them in at least one. Since for 16,052 transcripts two probes with opposite orientation were designed, bi-directional transcription appears a common phenomenon in the clam transcriptome. In fact, it is now clear that animal genomes are transcribed on both strands [24-26] and it is not to be excluded that part of the analyzed transcripts has a functional role [27]. In order to further explore this issue, microarray data for digestive glands and gills were analysed by examining sense-antisense probe pairs. After the exclusion of probes with missing data, absolute mean fluorescence signal values (f) obtained across biological replicates after normalization were divided into four classes ( $\mathrm{f}<10,10<=\mathrm{f}<100$, $100<=\mathrm{f}<1000, \mathrm{f}<=1000)$. Class assignment was conducted by considering the mean fluorescence value of the probe showing the lower signal for each pair comparison. Likewise, Fold Change (FC) between sense and antisense probes for each probe pair was assigned to four classes $(\mathrm{FC}<1.5,1.5<=\mathrm{FC}<3,3<=\mathrm{FC}<10$, FC $>=10$ ). Our results showed that $75 \%$ and $73.5 \%$ of probe-pairs had a signal ratio $>3$ in the gills and digestive gland, respectively, and $60 \%$ reported a signal ratio $>10$ in both tissues (see Table 5). This suggested a prevalent strand-orientation for the majority of transcribed regions in the clam genome. On the other hand, the absolute fluorescence for the "minor" strand was greater than 100 for $1,267(8.8 \%)$ and 985 (6.5\%) probe-pairs in the gills and digestive gland, respectively. In addition, a signal ratio $<3$ and a minimum of fluorescence $>100$ was recorded for 223 (1.6\%) probe-pairs in the gills and 151 (1\%) probe-pairs in the digestive gland. These results suggested that natural antisense transcripts (NATs) may be present in the clam transcriptome. Natural antisense transcripts have been originally identified by searching for EST collections, and appear to be widespread across species, although at different frequencies [28]. Various putative functions have been proposed for NATs [29]. For instance, an important role in the production of endogenous siRNAs is increasingly recognized [30]. A relevant question is whether NAT

Table 5 Comparison between sense and antisense probes for each probe pair

\begin{tabular}{|c|c|c|c|c|c|}
\hline & $\mathrm{FC}<1.5$ & $1.5<\mathrm{FC}<3$ & $3<\mathrm{FC}<10$ & $\mathrm{FC}>10$ & TOTAL \\
\hline \multicolumn{6}{|c|}{ GILLS } \\
\hline total & 1,958 & 1,635 & 2,118 & 8,629 & 14,340 \\
\hline F LS $<10$ & 1,683 & 1,197 & 1,319 & 4,920 & 9,119 \\
\hline $10<\mathrm{F} \mathrm{LS}<100$ & 194 & 296 & 592 & 2,872 & 3,954 \\
\hline $100<$ F LS $<1000$ & 66 & 119 & 162 & 707 & 1,054 \\
\hline F LS > 1000 & 15 & 23 & 45 & 130 & 213 \\
\hline \multicolumn{6}{|c|}{ DIGESTIVE GLAND } \\
\hline total & 2,061 & 1,909 & 2,646 & 8,411 & 15,027 \\
\hline F LS $<10$ & 1,783 & 1,451 & 1,936 & 5,530 & 10,700 \\
\hline $10<$ F LS $<100$ & 227 & 358 & 583 & 2,174 & 3,342 \\
\hline $100<$ F LS $<1000$ & 45 & 84 & 105 & 583 & 817 \\
\hline F LS > 1000 & 6 & 16 & 22 & 124 & 168 \\
\hline
\end{tabular}

The number of probes belonging to each Fold Change $(\mathrm{FC})$ classes (FC $<1.5,1.5<=\mathrm{FC}<3,3<=\mathrm{FC}<10$, FC $>=10$ ) is reported. Probes are also distinguished according to the mean fluorescence value of the probe showing the lower signal (FLS, Fluorescence Lower Signal). 
transcription is correlated, either positively or negatively, with the expression of their sense counterpart or it is independent of it. This was evaluated by analyzing gene/ transcripts represented with both sense and antisense probes pairs with SAM, in order to identify those that were differentially expressed in gills and digestive glands (see Table 6). Setting a threshold for FC to 1.5 and enforcing a relatively stringent FDR $(<0.01)$, for 688 genes both probes presented a significant q value. Of these, 658 showed concordant direction in sense/antisense regulation, while for 30 genes the two probes were up-regulated in the gills and the digestive gland, respectively. Under a less stringent FDR $(<0.1), 3,042$ probe-pairs resulted differentially regulated, with a proportion of paired probes expressed in opposite directions $(0.05)$ similar to the one observed above $(0.04)$..

\section{Clam genomic markers for environmental monitoring}

A wide array of biochemical, cellular, and whole-organism markers have been applied to evaluate the biological effects of different types of pollutants in aquatic animals and to assess the status of marine ecosystems [31,32]. For instance, over-expression of metallothioneins (MTs) has been associated with exposure to heavy metals, inhibition of acetylcholinesterase (AChE) with organophosphorous, pesticide exposure, and induction of Vitellogenin (Vg) proteins (egg-yolk precursors) with the presence of xenoestrogens (endocrine-disruptors).

In the R. philippinarum platform developed in this study at least four transcripts (ruditapes_c21946, ruditapes_c30181, ruditapes_c7664, ruditapes_c12315) that appear to be AChE precursors and ten different expressed sequences (ruditapes_lrc32058, ruditapes_lrc32676, ruditapes2_c61, ruditapes2_c830, ruditapes2_lrc2117, ruditapes2_lrc4331, ruditapes2_lrc4377, ruditapes2_lrc4388, ruditapes2_lrc5136, ruditapes2_lrc5747) coding for a putative metallothionein were incorporated into the microarray. Finally, a transcript (ruditapes_c16240) showing a significant match with invertebrate $\mathrm{Vg}$ proteins was also included. It is worth mentioning that the lack of a specific anti-Vg antibody for many species impairs direct measure of such biomarker, and only indirect estimates of $\mathrm{Vg}$ concentration can be obtained using an alkali-labile phosphate (ALP) assay.
At the cellular level, loss of lysosomal membrane integrity has been observed as a consequence of oxidative stress induced by several class of chemicals. Reduced lysosomal membrane stability is also linked to increased autophagy [33]. To which extent these biochemical and cellular markers might be mirrored by gene expression markers present in RuphiBase based on GO-CC annotation, 73 lysosomal proteins including several cathepsins and other hydrolases could be found in the current clam transcriptome. Of note is a putative homolog (ruditapes_c23093) for Autophagic Transcript 12 (ATG12), an ubiquitin-like modifier necessary for macroautophagy, while several RuphiBase entries match with p14/ROBLD3, which is part of a protein complex that recruits mTOR (Mammalian Target Of Rapamycin), a key negative regulator of autophagy, to the lysosome membrane [34]. Further studies may be conducted to test whether chemical pollutants affecting lysosomal stability can induce alterations in expression levels of lysosomal and/or autophagy-related proteins. Indeed, tributyltin chloride has recently been shown to inhibit mTOR in neuronal cells [35].

A separate discussion is required for GSTs, which constitute a large protein family [36], with a pivotal role in detoxification of xeno-compounds. These enzymes, involved in the conjugation of reduced glutathione to electrophilic centers on a wide variety of substrates, contribute to the detoxification of endogenous compounds (e.g. peroxidised lipids) as well as xenobiotics, and an increased GST activity has been observed after exposure to a broad set of pollutants. A total of 118 RuphiBase entries were annotated as putative GSTs of different subfamilies. Apart from four microsomal GSTs, putative cytosolic GSTs were divided into five subfamilies: 61 GST- $\sigma, 21$ GST- $\theta, 11$ GST- $\pi, 7$ GST- $\mu, 4$ GST $-\omega$ and 10 unclassified GST isoforms. Comparison of clam transcripts against single-species complete transcriptomes revealed the highest number of matches (69) with zebrafish., $33 \alpha$-like GSTs, 7 GST- $\mu$, and 29 GST- $\pi$ isoforms were identified. Human-clam comparison returned only 36 matches, although subfamily classification was more complex with 6 GST- $\mu, 10$ GST- $\pi, 1$ GST- $\xi, 15$ GST- $\theta$ and 4 GST- $\omega$ isoforms. To further explore the incongruence between different annotations, we conducted a detailed analysis of the 29 GST- $\pi$ isoforms classified on

Table 6 Gene/transcripts represented with both sense and antisense probe pairs differentially expressed between gills and digestive gland (FC threshold set to 1.5)

\begin{tabular}{cccc}
\hline q-value & Discordant S-AS pairs & \multicolumn{2}{c}{ Concordant S-AS pairs } \\
\cline { 3 - 4 } & & UP-regulated in digestive gland & UP-regulated in gills \\
\hline$<\mathbf{1 8 \%}$ & 898 & 532 & 3,489 \\
$<\mathbf{1 0} \%$ & 176 & 195 & 2,671 \\
$<\mathbf{1 . 1} \%$ & 30 & 97 & 561 \\
\hline
\end{tabular}


the basis of similarity against zebrafish. Eight transcripts showed an open reading frame (ORF) encoding a putative complete coding sequence for GST, while four transcripts presented an ORF encoding a partial GST coding sequence. The remaining sequences (17) contained either partial or complete GST coding sequences with reading frames interrupted by stop codons. Comparative sequence analysis revealed that these frame-shifts were always due to insertions/deletions (indels) within short homopolymeric stretches, a known problem with 454 pyrosequencing technology [37]. A phylogenetic tree was then reconstructed (see Figure 3) using the eight complete RuphiBase GSTs together with the best matching protein from GenBank as well as from human and zebrafish putative homologs (see Methods). It is clear that the classification based on comparison with zebrafish is incorrect, hiding two groups of sequences, one belonging to the $\sigma$ subfamily, the other containing bona fide GST- $\pi$ proteins. Using Blast results, the remaining 21 partial and/or interrupted ORFs were assigned to one GST sequence present in the tree in Figure 3, to obtain a classification of all 29 sequences originally assigned to the $\pi$ subfamily. A tree-like representation is better suited to analyze and display the evolution of protein families or sub-families including a large number of multiple gene copies. The gene genealogy in Figure 3 is just an example

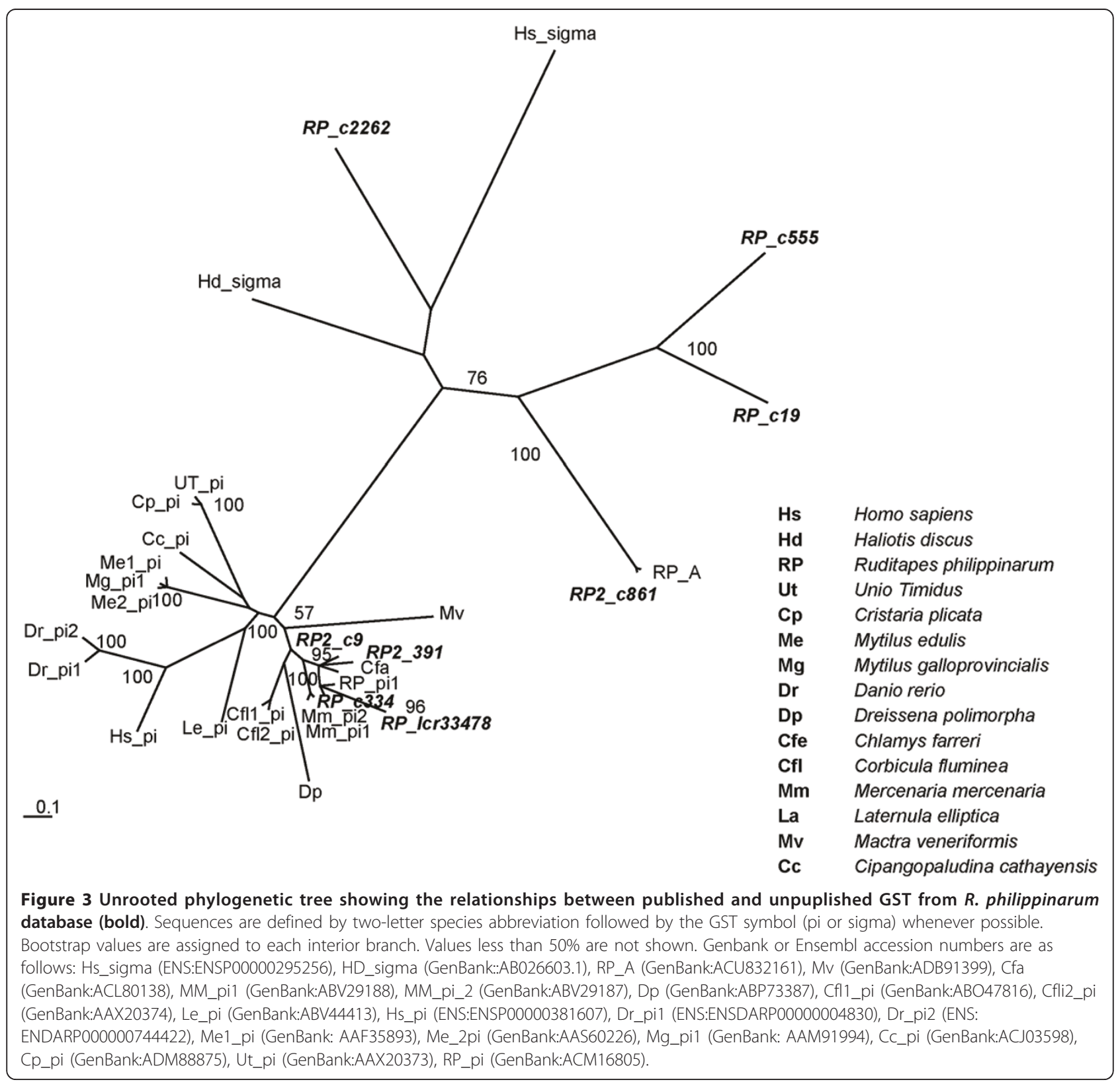


of what is expected in case of a significant multiplicity is observed, as is the case of the the subset of GST-encoding transcripts analyzed here. To which extent different GST sequences reflect the presence of distinct GST loci in the clam genome? Pairwise comparison of best matching clam sequences across 29 GST-encoding transcripts (average length $742 \mathrm{bp}$, range 286-1130 bp) showed that one third of sequence differences (145 out of 14,042 surveyed bp, average $1 \%$, range $0-3 \%$ ) was due to indels, a likely consequence of sequencing errors, but the majority (269, average $1.9 \%$ range $0.1-11 \%$ ) are nucleotide replacements, which are much less frequently observed with 454 pyrosequencing technology. For 15 sequences the closest match has $1 \%$ sequence divergence, for 11 more than $2 \%$. Therefore, although part of the observed sequence diversity might be explained as different alleles of single GST loci, a substantial number of GST isoforms appear to be encoded by different genes. It should also be reminded here that this is a conservative estimate because in most comparisons only a fragment of the total sequence for each transcript, generally the one encompassing the coding region, was aligned (average 79\%, range 33-100\%). A similar problem of classification affects 21 sequences assigned to the $\theta$ GST subfamily, with 18 transcripts finding a Pleuronectes platessa (plaice) $\theta$ GST as their best match in SwissProt. This plaice $\theta$ GST has been recently re-assigned to a novel GST class, $\rho$ [38]. Therefore, most clam sequences attributed to the $\theta$ class might actually belong to this specific GST protein group, similar to the only putative $\theta$ GST from a mollusk species isolated so far [39]. On the other hand, the remaining three sequences matched either a mammalian or a avian $\theta$ GST protein and might represent the first evidence of molluscan $\theta$ GSTs.

A correct classification of GST proteins is often difficult [36], but it is mostly important when correlating the expression of different GST-encoding genes with exposure to specific groups of environmental pollutants, as the various GST classes show diverse substrate specificities, catalytic properties, and tissue distribution.

\section{Gene expression profiling of Manila clam sampled in a polluted area of the Venice lagoon}

The Venice lagoon, the largest in the Mediterranean sea, is characterized by the presence of complex mixtures of xenobiotics, derived from both industrial and domestic effluents, which reach higher concentrations in specific areas, mainly close to the industrial zone of Marghera. Gene expression profiles of digestive glands and gills from Manila clams harvested in a cleaner area (Alberoni) of the Venice lagoon were compared to the corresponding tissues of clams sampled within the industrial area. This area shows high levels of contamination with different xenobiotics, as confirmed in various studies [40] and it is currently restricted for clam harvesting.
For each tissue and comparison, raw and normalized fluorescence have been deposited in the GEO data base [22] under accession number GEO:GSE27194. A twounpaired class SAM test was carried out separately for digestive glands and gills on normalized data, enforcing a False Discovery Rate (FDR) of $10 \%$ and Fold Change (FC) of 1.5.

Comparison of expression profiles between the two areas revealed a remarkably large number of differentially expressed transcripts in both tissues, respectively 1,127 in the digestive gland and 2,432 in the gills. A limited set of transcripts (99) showed differential expression in both tissues. Fold-change differences varied from -174- to 1,446-fold in the gills, with a prevalence for upregulated transcripts $(1,412)$ compared to down-regulated ones $(1,020)$ in samples collected in the industrial area. This trend is reversed for transcripts displaying the strongest signal, as 93 probes showed FC $>5$ (13 with FC $>10$ ), whereas 120 ones presented FC $<-5$ (22 with $\mathrm{FC}>10)$. In the digestive gland, FC ranged between -30- and 62-fold. A significant bias toward up-regulated transcripts $(852,75 \%$ of all differentially expressed sequences, binomial test $\mathrm{p}<0.00001$ ) was observed in animals sampled in the industrial area, a bias that was even stronger for transcripts showing FC larger than \pm 5-fold (94 with FC $>5,26$ with $\mathrm{FC}<-5$; binomial test $\mathrm{p}$ $<0.000001)$.

Putative annotations were obtained respectively for 321 digestive gland- and 830 gills-specific transcripts by comparison against the NCBI protein non redundant database. When using the zebrafish transcriptome as a reference, respectively 247 (digestive gland) and 730 (gills) differentially expressed sequences could be associated with one D. rerio Ensembl Gene IDs (see Addition file 4).

In a comparison between natural population samples different environmental and/or physiological factors can influence gene expression profiles. The objective of the present study was to assess the role of chronic exposure to high levels of chemical pollution. To control for the effects of other factors, histological examination of collected animals was carried out showing similar sex ratio (1:1), comparable levels of parasitic contamination, average size (12.3 gr vs $14 \mathrm{gr}$ ), and reproductive stage (data not shown). Water temperature and salinity showed no significant differences between the two analyzed areas. Indeed, the temperature and salinity recorded at the time of sampling were $18^{\circ} \mathrm{C}$ and $32 \%$ and $20^{\circ} \mathrm{C}$ and $34 \%$ in Marghera and Alberoni respectively. Likewise, it seems quite difficult that strong genetic differentiation occurs at a such a small geographic scale (few kilometres), in the presence of a planktonic larval phase and a sustained water circulation within the Venice lagoon. Although evidence on population genetics for the 
Manila clam is limited, it has been shown that no genetic structure was present across four population samples in the Adriatic Sea, including the Venice lagoon [41].

Systematic functional annotation of differentially expressed transcripts, carried out through enrichment analysis in DAVID (see Methods) confirmed a putative role of pollution in the regulation of gene expression in the examined samples, especially in the digestive gland. This organ has been generally associated with response to pollutants, particularly with detoxification of xenobiotics. Three significantly enriched GO_BP terms (see Table 7), response to organic substances (GO:0010033), to cadmium ion (GO:0046686), and to methylmercury (GO:0051597), two enriched KEGG pathways, drug metabolism (dre00982) and metabolism of xenobiotics by cytochrome P450 (dre00980), support the evidence that the digestive gland is responsible for detoxification of environmental pollutants and suggests it as a target organ for the detection/identification of biomarkers of

Table 7 GO terms significantly over-represented, among genes differentially expressed, between Alberoni and Marghera samples, in both gills and digestive gland

\begin{tabular}{|c|c|c|c|c|}
\hline \multicolumn{5}{|c|}{ DAVID analysis of digestive gland differential expressed genes } \\
\hline Category & Term & Count & p-value & F.E. \\
\hline \multirow[t]{5}{*}{$\mathrm{BP}$} & GO:0007018 microtubule-based movement & 4 & 0.014259 & 6.969072 \\
\hline & GO:0007017 microtubule-based process & 5 & 0.021639 & 4.35567 \\
\hline & GO:0010033 response to organic substance & 4 & 0.040861 & 4.878351 \\
\hline & GO:0046686 response to cadmium ion & 3 & 0.078833 & 6.097938 \\
\hline & GO:0051597 response to methylmercury & 3 & 0.078833 & 6.097938 \\
\hline \multirow[t]{4}{*}{$\overline{M F}$} & GO:0005856 cytoskeleton & 11 & 0.008012 & 2.50387 \\
\hline & GO:0015630 microtubule cytoskeleton & 5 & 0.028246 & 4.021368 \\
\hline & GO:0005874 microtubule & 4 & 0.030885 & 5.361823 \\
\hline & GO:0045259 proton-transporting ATP synthase complex & 4 & 0.09956 & 3.446886 \\
\hline \multirow[t]{3}{*}{$\mathrm{KP}$} & dre04510:Focal adhesion & 8 & 0.035313 & 2.421429 \\
\hline & dre00982:Drug metabolism & 4 & 0.042809 & 4.708333 \\
\hline & dre00980:Metabolism of xenobiotics by cytochrome P450 & 4 & 0.042809 & 4.708333 \\
\hline \multicolumn{5}{|c|}{ DAVID analysis of gills differential expressed genes } \\
\hline Category & Term & Count & p-value & F.E. \\
\hline \multirow[t]{11}{*}{$\mathrm{BP}$} & GO:0044267 cellular protein metabolic process & 75 & 0.002721 & 1.314444 \\
\hline & GO:0006412 translation & 43 & 0.004311 & 1.463856 \\
\hline & GO:0045333 cellular respiration & 10 & 0.008891 & 2.490526 \\
\hline & GO:0015980 energy derivation by oxidation of organic comp. & 10 & 0.008891 & 2.490526 \\
\hline & GO:0034645 cellular macromolecule biosynthetic process & 54 & 0.01233 & 1.323979 \\
\hline & GO:0019538 protein metabolic process & 90 & 0.012991 & 1.209886 \\
\hline & GO:0006091 generation of precursor metabolites and energy & 18 & 0.037073 & 1.607094 \\
\hline & GO:0006457 protein folding & 13 & 0.046318 & 1.7576 \\
\hline & GO:0010467 gene expression & 56 & 0.063065 & 1.210009 \\
\hline & GO:0044237 cellular metabolic process & 125 & 0.063116 & 1.103545 \\
\hline & GO:0009060 aerobic respiration & 5 & 0.065749 & 2.9575 \\
\hline \multirow[t]{8}{*}{ MF } & GO:0003735 structural constituent of ribosome & 38 & 4.49E-04 & 1.689704 \\
\hline & GO:0005198 structural molecule activity & 43 & $7.11 \mathrm{E}-04$ & 1.593361 \\
\hline & GO:0015078 hydrogen ion transmembrane transporter activity & 14 & 0.035716 & 1.766618 \\
\hline & GO:0016859 cis-trans isomerase activity & 7 & 0.057275 & 2.334459 \\
\hline & GO:0003755 peptidyl-prolyl cis-trans isomerase activity & 7 & 0.057275 & 2.334459 \\
\hline & GO:0008092 cytoskeletal protein binding & 12 & 0.07344 & 1.697789 \\
\hline & GO:0015075 ion transmembrane transporter activity & 23 & 0.07676 & 1.394612 \\
\hline & GO:0003924 GTPase activity & 6 & 0.09088 & 2.334459 \\
\hline \multirow[t]{3}{*}{$\mathrm{KP}$} & dre03010:Ribosome & 39 & $9.90 \mathrm{E}-07$ & 2.003182 \\
\hline & dre04260:Cardiac muscle contraction & 13 & 0.007105 & 2.136727 \\
\hline & dre00630:Glyoxylate and dicarboxylate metabolism & 4 & 0.094374 & 3.287273 \\
\hline
\end{tabular}

Details about "Biological process", "Molecular function" and "KEGG pathways" represented by at least 2 genes up regulated in each tissue. 
pollution. Manual annotation of significant transcripts identified additional genes in the digestive gland with a known role in the response to environmental pollution.

Four transcripts encoding MTs (ruditapes2_lrc4377, ruditapes_lrc32058, ruditapes2_c830, ruditapes2_lrc4331) and two encoding sulfotransferase (SULT) (ruditapes_c20565, ruditapes_c28883) (see Additional file 4) are over-expressed in samples from the industrial zone. MTs provide protection against metal toxicity, are involved in the regulation of physiological metals ( $\mathrm{Zn}$ and $\mathrm{Cu}$ ) and provide protection against oxidative stress. MTs can be induced either by essential metals $(\mathrm{Cu}$ and $\mathrm{Zn})$ or non-essential ones $(\mathrm{Cd}, \mathrm{Ag}$ and $\mathrm{Hg}$ ) in both vertebrates and invertebrates. Increased levels of MTs after experimental exposure to high $\mathrm{Cu}$ concentrations had been already reported in the digestive gland of $R$. philippinarum [42], while higher MT protein expression had been found in clams collected at sites nearby the industrial zone of Marghera [43-45].

SULTs, a family of phase II detoxification enzymes, are involved in the homeostasis of endogenous compounds as well as in the protection against xenobiotics. It is well known that sulfated products of environmental xenobiotics are more water-soluble and easily excreted from the body. Channel catfish (Ictalurus punctatus) exposed to Polycyclic aromatic hydrocarbons (PAHs) showed a marked induction of phenol-type sulfotransferase enzyme activity [46]. In addition, SULT1 was upregulated in Gadus morhua male sampled in two contaminated sites of western Norway [47]. Although these genes play a documented role in the defense from chemicals [48], to our knowledge they have never been proposed as biomarkers in bivalve species.

AChE enzymatic activity is inhibited in response to organophosphate insecticides and exposure to other pollutants. Eight different clam transcripts encoding a peptide with putative cholinesterase activity are represented in the $R$. philippinarum microarray.

In the present study, an AChE-encoding gene (ruditapes_c12315) was over-expressed in both gills and digestive glands of clams sampled in Marghera. A similar finding has been already reported by Somnuek et al. (2009) [49], who demonstrated up-regulation of AChE gene expression in hybrid catfish exposed to chlorpyrifos and proposed this gene as biomarker for detecting the effects of organophosphate insecticides. The apparently opposite transcriptional response on $\mathrm{AChE}$ gene expression likely represents a compensatory modification to counteract inhibition of enzyme activity after xenobiotic exposure.

Several GST-coding transcripts were also found upregulated in samples collected in the polluted area. Glutathione S-transferase (GST) catalyses the conjugation of reduced glutathione to electrophilic centers on a wide variety of substrates. This activity detoxifies endogenous compounds (e.g. peroxidised lipids) as well as xenobiotics and an increased of GSTs activity has been observed after exposure to a broad set of xenobiotics.

GST-coding genes that are over-expressed in clams sampled in Marghera either in the gills or in the digestive gland are different, except for a single transcript, which is up-regulated in both tissues (Table 8). Tissuespecific expression and sensitivity to dose/type of chemicals has been already reported in bivalves [50,51], suggesting a complex regulation of these effectors in the response to toxicants. Results obtained in the present study show also that various GST classes/isoforms are putatively involved in response to toxicants and emphasize the need for a proper classification of GST-coding genes. Five classes of cytosolic GSTs are differentially regulated together with a microsomal isoform in samples from the industrial area. Of special interest are two distinct genes, both encoding a GST- $\theta$ isoform. As mentioned previously GSTs belonging to the $\theta$ class have never been isolated in molluscs, and GST $\theta$ s apparently represent a numerically minor component of the GST arsenal in the Manila clam ( 3 putative $\theta$ isoforms among over 100 GST-encoding transcripts), yet two GST $\theta$-like genes showed marked up-regulation in putatively contaminated samples of the same species (see Table 8). GST-like activity is one of the most relevant biochemical parameters that are measured in environmental studies on chemical pollution, commonly using 1-choloro-2,4-dinitrobenzene (CDNB) as a substrate $[52,53]$. GST- $\theta$ enzymes, however, have a peculiar substrate specificity. GST- $\theta 1 \mathrm{KO}$ mice showed no difference for in vivo processing of CDNB, while GST-activity against other substrates [1,2-epoxy-3-(p-nitrophenoxy) propane (EPNP), dichloromethane (DCM), and 1,3-bis (2-chloroethyl)-1-nitrosourea (BCNU)] was significantly lower after GST- $\theta 1$ gene deletion. The results reported in the present study suggest that measuring GST-like enzymatic activity might not completely represent that

\begin{tabular}{|c|c|c|c|}
\hline Contig & GST subfamily & Tissue & Fold Change \\
\hline ruditapes_s39905 & $\sigma$ & gills & 4.2 \\
\hline ruditapes_Irc39890 & $\rho$ & gills & 1.9 \\
\hline ruditapes_Irc31893 & $\mu$ & gills & 1.8 \\
\hline ruditapes_c17817 & $\theta$ & gills & 5.1 \\
\hline ruditapes_c37712 & $\pi$ & gills & 2.2 \\
\hline ruditapes_s39905 & $\sigma$ & digestive gland & 4.2 \\
\hline ruditapes2_c352 & $\mu$ & digestive gland & 1.6 \\
\hline ruditapes2_c567 & $\theta$ & digestive gland & 2 \\
\hline ruditapes2_c72 & microsomal & digestive gland & 3.3 \\
\hline
\end{tabular}


complex GST-based response to toxicants in bivalves. Accurate characterization of GST-encoding genes in species that are used for environmental monitoring coupled with transcriptome analysis could provide a more precise analysis of such a response, differentiating tissue-specificity and disentangling GST isoform diversity.

\section{Conclusions}

Whole-transcriptome analysis holds the promise to shed light on the genetic mechanisms underlying cellular and organismal response to physiological and pathological conditions (environmental stress, infections, chemical pollution). This is of particular importance for improved shellfish aquaculture and for cost-effective environmental monitoring. The aim of the present paper was to lay the foundations for transcriptomics in the Manila clam. To which extent this goal has been achieved? As demonstrated in previous studies [54], the use of nextgeneration sequencing technology yielded a number of expressed sequences unattainable until only recently. In our study, sequence assembly, annotation and development of a dedicated database resulted in a searchable, functionally annotated transcriptome for R. philippinarum (RuphiBase), which was then used to design a species-specific in-situ synthesized oligo microarray. This genomic platform has proven to provide reliable and highly reproducible results for global gene expression profiling [10-18]. Moreover, validation of the clam oligo microarray showed tissue-specific expression profiles and highly significant correlations across biological replicates. The current version of RuphiBase appears to offer already a good representation of the clam transcriptome, as shown by the broad array of potential markers of response to xenobiotics. Of particular relevance is the large number ( $>100)$ of GST-encoding transcripts observed in the Manila clam, which suggested a potential relationship between filter-feeding behaviour, ability to cope with high levels of pollution and availability of a wide array of detoxifying enzymes. The possible use of this microarray platform for toxicogenomic studies has been also demonstrated by comparative analysis of digestive glands and gills pool of Manila clam sampled in areas with different levels of chemical pollution of the Venice Lagoon.

On the other hand, despite the use of ultra-high throughput sequencing on normalized cDNA libraries constructed from all adult tissues, representation of the clam transcriptome is still incomplete. For instance, the signaling pathway for autophagy consists of at least 18 different components [55], yet only one of these, ATG12, a protein involved in autophagic vescicle assembly, was identified. The problem of incomplete representation of protein-coding transcripts will likely be solved in the near future, when reduction of sequencing costs and an increase in sequencing throughput will allow a much deeper sequence coverage even for non-model species transcriptomes. A more difficult issue to solve is the limited percentage of clam transcripts that can be matched against a known protein-coding gene. The large phylogenetic distance of the phylum Mollusca from other metazoan model species (e.g. Drosophila melanogaster, Caenorhabditis elegans, Danio rerio, Mus musculus, Homo sapiens) greatly reduces the power of a comparative approach for functional annotation. The only molluscan genome sequenced so far is that of $L$. gigantea, a gasteropod snail, which is functionally and evolutionarily distant from the class Bivalvia.

To conclude on a positive note, the next "call on (genomic) stage" is for the Pacific oyster, Crassostrea gigas. For this bivalve mollusk species, a high quality draft genome sequence is expected in 2011 thanks to the efforts of the Oyster Genome Consortium. Furthermore, worldwide aquaculture production of oysters amounts to over 4 million metric tons. The economic importance of the Pacific oyster has fuelled a large number of studies on the ecology, physiology, immunology, and genetics of $C$. gigas populations, and the possibility of targeted gene knock down has been recently demonstrated [56]. The opportunity of having a bivalve model species available would allow a more accurate genome annotation for other important molluscs such as the Manila clam.

\section{Methods}

Sampling, cDNA library costruction and sequencing

Samples of $R$. philippinarum were bought in a local market in Faro. In order to improve RNA representatively, clams were stressed by submitting them to quick changes of temperature and salinity prior to be sacrificed. Total RNA was extracted from all tissues of 20 individuals using the acid guanidinium thiocyanate-phenol-chloroform method [57].

Two libraries were constructed, one using a mixture of adult tissues and a second one using gonadal tissues and 2 to $4 \mathrm{~mm}$ long larvae.

A cDNA library was constructed using equal amounts of RNA and normalized for sequencing. The SMART (Switching Mechanism At 5' end of RNA Template) kit from BD Biosciences Clontech was used to construct the cDNA libraries which were later normalised using the duplex-specific nuclease (DSN) method [58].

Approximately $15 \mu \mathrm{g}$ of normalized cDNA were used for sequencing library construction at the Max Planck Institute, following procedures described in [59]. Sequencing was performed using GS FLX Titanium series reagents and using one single region on a Genome Sequencer FLX instrument. Bases were called with 454 
software by processing the pyroluminescence intensity for each bead-containing well in each nucleotide incorporation. Reads were trimmed to remove adapter sequences.

\section{Contigs assembly}

A total of 457,717 sequence reads were produced using Roche 454 FLX technology from the normalized cDNA library constructed using a mixture of adult tissues (see above). The same library was previously used to obtain 2,866 ESTs with Sanger sequencing. An additional set of 2,790 ESTs was available from a second normalized cDNA library (whole larvae and adult gonads). In addition, 51 mRNA sequences available in NCBI (as to 11th November 2009) for $R$. philippinarum were available.

454 Sequence reads and all previously ESTs accessible in the NCBI database were then assembled into contigs, representing putative transcripts, by using a custom procedure based on two runs of MIRA3 assembly [60] and quality-based filtering. All contigs obtained with the first run of hybrid assembly were used for a second run to eliminate contig redundancy. Threshold values on contigs length and sequence quality were then applied to obtain a final set of contigs representing $R$. philippinarum transcripts.

\section{Transcripts annotation}

The Basic Local Alignment Search Tool (BLAST) was used to perform annotation of $R$. philippinarum contigs. Batch Blast similarity searches for the entire set of contigs were locally conducted against NCBI (National Centre for Biotechnology Information) amino acidic non redundant (nr) database (release of October 4 2009) using Blastx option. Alignments with an E-value of at most 1 E-3 were considered significant and up to 20 hits per contig were taken into account.

To improve the number of annotated contigs five different approaches were attempted (see Additional file 1): i) blastx searches (cut off e-value of $<1.0 \mathrm{E}$-3) against protein database UniProtKB/SwissProt and UniProtKB/ TrEMBL [61], ii) blastx (cut off e-value of < 1.0 E-3) and blastn (cut off e-value of $<1.0$ E-5) searches against proteins and high quality draft trascriptomes of Danio rerio, Gasterosteus aculeatus, Oryzias latipes, Takifugu rubripes, Tetraodon nigroviridis, Homo sapiens, Drosophila melanogaster available on Ensembl Genome Browser (release 56) [62], iii) blastx (cut off e-value of $<1.0$ E-3) and blastn (cut off e-value of $<1.0$ E-5) searches against proteins, transcripts and assembly scaffolds of Lottia gigantea v1.0 database [63], iv) blastn search (cut off e-value of $<1.0$ E-5) against D. rerio, L. gigantea, $O$. latipes, T. rubripes, Salmo salar, H. sapiens, Oncorhynchus mykiss databases stored in NCBI UniGene database [64], v) blastn search (cut off e-value of $<1.0$ E-5) against Crassostrea gigas transcripts database [65] and Argopecten irradians EST database [66].

The Gene Ontology (GO) terms associations for "Biological process", "Molecular function" and "Cellular component" were performed using Blastx algorithm against the NCBI amino acid nr database implemented in Blast2GO software [67]. The "Generic GO slim" [68] set of the CateGOrizer program [69] was used to have an overview of the gene ontology content by simplifying the results of the GO annotation.

\section{DNA microarray design}

Probe design started with selection of target sequences to be represented onto the $R$. philippinarum microarray. All annotated entries $(9,747)$ were included. Non annotated transcripts were considered only if sequence length was $\geq 400 \mathrm{bp}$ and average Phred sequence quality was $\geq 30$, yielding 24,291 target sequences. As most sequence reads were obtained from a non directional cDNA library, sense strand orientation was inferred putatively from that of homologuous protein sequences of other species (see Methods).

One probe for annotated transcripts with known orientation was designed to construct a high-density oligoDNA microarray, while two probes with both orientations were designed for contigs with ambiguous orientation. The same strategy was applied to unknown unique transcripts. For 8,239 contigs, the putative orientation was unambiguous across different databases and a single sense probe was designed. Two probes with opposite orientation (sense and antisense) were designed for a fraction of clam annotated transcripts (1,508 contigs) with ambiguous putative orientation and for non annotated sequences $(14,544)$. Probe design was carried out using the Agilent eArray interface [70], which applies proprietary prediction algorithms to design 60 mer oligoprobes. Microarrays were synthesized in situ using the Agilent ink-jet technology with a $4 \times 44 \mathrm{~K}$ format. Each array included default positive and negative controls.

A total of 40,332 out of 40,343 (99.9\%) probes, representing 24,281 R. philippinarum transcripts were successfully obtained. Of these, 2,000 probes designed on known-orientation transcripts, were synthesized in duplicate on the array in order to test for "reproducibility-within-array". The percentage of annotated transcripts represented on the microarray was $40.1 \%$. Probe sequences and other details on the microarray platform can be found in the GEO database [22] under accession number GEO:GPL10900.

\section{Sample collection, RNA extraction, labeling and hybridization}

The common bivalves $R$. philippinarum were collected during autumn 2009 in two different areas of Venice 
Lagoon characterized by different levels of environmental pollutants: Marghera and Alberoni (see Additional file 5).

Digestive gland and gills were dissected from 20 Manila clamsfor each sampling area. Four and three independent pools, for digestive gland and gills respectively, each consisting of 5 digestive gland or gills, were created.

Total RNA was extracted from pooled tissue samples using the RNAeasy Mini Kit (Qiagen, Hilden, Germany) following the manufacturer's instructions. RNA concentration was determined using a UV-Vis spectrophotometer, NanoDrop ${ }^{\circledR}$ ND-1000 (NanoDrop Technologies, Wilmington, USA). RNA integrity and quality was finally estimated on an Agilent 2100 Bioanalyzer (Agilent Technologies, Palo Alto, CA).

Sample labeling and hybridization were performed according to the Agilent One-Color Microarray-Based Gene Expression Analysis protocol. Briefly, for each pool $200 \mathrm{ng}$ of total RNA were linearly amplified and labeled with Cy3-dCTP. A mixture of 10 different viral poly-adenilated RNAs (Agilent Spike-In Mix) was added to each RNA sample before amplification and labeling, to monitor microarray analysis work-flow. Labeled cRNA was purified with Qiagen RNAeasy Mini Kit, and sample concentration and specific activity (pmol Cy3/ $\mathrm{gg}$ cRNA) were measured in a NanoDrop ${ }^{\circledR}$ ND-1000 spectrophotometer. A total of 1,650 ng of labeled cRNA was prepared for fragmentation adding $11 \mu \mathrm{l} 10 \mathrm{X}$ Blocking Agent and $2.2 \mu \mathrm{l}$ of $25 \mathrm{X}$ Fragmentation Buffer, heated at $60^{\circ} \mathrm{C}$ for $30 \mathrm{~min}$, and finally diluted by addition with 55 $\mu \mathrm{l} 2 \mathrm{X}$ GE Hybridization buffer. A volume of $100 \mu \mathrm{l}$ of hybridization solution was then dispensed in the gasket slide and assembled to the microarray slide (each slide containing four arrays). Slides were incubated for $17 \mathrm{~h}$ at $65^{\circ} \mathrm{C}$ in an Agilent Hybridization Oven, subsequently removed from the hybridization chamber, quickly submerged in GE Wash Buffer 1 to disassembly the slides and then washed in GE Wash Buffer 1 for approximately 1 minute followed by one additional wash in pre-warmed $\left(37^{\circ} \mathrm{C}\right) \mathrm{GE}$ Wash Buffer 2.

\section{Data acquisition and analysis}

Hybridized slides were scanned at $5 \mu \mathrm{m}$ resolution using an Agilent G2565BA DNA microarray scanner. Default settings were modified to scan the same slide twice at two different sensitivity levels (XDR Hi 100\% and XDR Lo $10 \%)$. The two linked images generated were analyzed together and data were extracted and background subtracted using the standard procedures contained in the Agilent Feature Extraction (FE) Software version 9.5.1. The software returns a series of spot quality measures in order to evaluate the goodness and the reliability of spot intensity estimates. All control features (positive, negative, etc.), except for Spike-in (Spike-in Viral RNAs), were excluded from subsequent analyses. Spike-in control intensities were used to identify the best normalization procedure for each dataset. After normalization, spike intensities are expected to be uniform across the experiments of a given dataset. Normalization procedures were performed using $\mathrm{R}$ statistical software [71]. Quantile normalization always outperformed cyclic lowess and quantile-normalized data were used in all subsequent analyses.

Statistical tests implemented in the program Significance Analysis of Microarray (SAM) [72] were used to identify differentially expressed genes between digestive gland and gill tissues. The same approach was used to identify differentially expressed genes in both digestive glands and gills between MA and AL sampled individuals.

Pearson correlation coefficients were estimated within and among arrays with Statgraphics Centurion XVI to evaluate repeatability and precision of the obtained microarray data.

\section{Functional enrichment of differentially expressed genes}

Functional annotation analysis of differentially expressed genes was performed using the DAVID (Database for Annotation, Visualization and Integrated Discovery) web-server [23].

Functional annotation of differentially expressed genes between gills and digestive glands was achieved using DAVID software. "Biological process", "Molecular function" and "Cellular component" annotation was carried out by setting gene count $=10$ and ease $=0.05$. KEGG pathway analysis was then performed with gene count = 4 and ease $=0.05$. David analyses of differentially expressed genes between Manila clam tissues sampled in Alberoni and Marghera were performed by setting gene count $=2$ and ease $=0.1$ Since DAVID databases contain functional annotation data for a limited number of species, it was necessary to link $R$. philippinarum transcripts with sequence identifiers that could be recognized in DAVID (Ensembl Human Gene IDs and Ensembl Zebrafish Gene IDs). This was carried out through dedicated Blast searches implemented as follows: i) blastx and blastn options were both used to search significant matches of the Manila clam sequences directly against human Ensembl proteins and transcripts respectively, ii) a first search was performed using either blastn or blastx against all zebrafish Ensembl proteins. Finally, Homo sapiens Ensembl Gene IDs were obtained from the corresponding Ensembl protein entries using the BIOMART data mining tool [73].

\section{Evolutionary analyses}

Evolutionary analyses were performed to determine patterns of divergence of the GST genes in $R$. 
philippinarum and to define putative orthology between GST genes in different species. Protein sequences of GST domains were aligned using TCoffee [74] applying default settings, while GBlock [75] was used to eliminate poorly aligned positions and divergent regions prior to phylogenetic analysis.

GST sequences described from Homo sapiens, Haliotis discus, Unio timidus, Cristaria plicata, Mytilus edulis, Mytilus galloprovincialis, Danio rerio, Dreissena polymorpha, Chlamys farreri, Corbicula fluminea, Mercenaria, mercenaria, Laternula elliptica, Mactra veneriformis, Cipangopaludina cathayensis were included in the alignment.

Phylogenetic trees were inferred by the maximum likelihood (ML) method [76] using the Phyml 2.4.4 program [77]. Non-parametric bootstrap resamplings were performed to evaluate the robustness of tree topology.

\section{Additional material}

Additional file 1: Summary of Blastx (E-value $<10-3$ ) and Blastn (Evalue $<10-5$ ) similarity searches on several protein and nucleotide databases for R.philippinarum transcripts annotation.

Additional file 2: GO terms associated to R. philippinarum transcripts represented in the microarray using "Generic GO slim" in Blast2GO software. Details about "Biological process", "Molecular function" and "Cellular component" GO terms.

Additional file 3: Lists of annotated differentially expressed genes in digestive gland compared to gills. Score, Fold change, q-value and annotation on several protein and nucleotide database were also reported

Additional file 4: List of significant probes identified by SAM analysis by comparison of digestive gland and gills of Manila clam sampled in Alberoni and Marghera. Significant probes in common between both tissue were also reported. Down-regulated genes in Marghera samples are highlighted in green while over expressed genes are highlighted in red. For each transcript, fold change, q-value, annotation and homologs zebrafish Ensembl Gene IDs (ENDARP and ENDARG) are reported.

Additional file 5: Sampling site in the Lagoon of Venice. Map of the Venice Lagoon showing Manila clam sampling sites.

\section{Acknowledgements}

We would like to thank Lino Pavan for providing access to the samples and TINAMENOR S.A. for providing clam larvae. This work was partially supported by a grant from European Union-funded Network of Excellence "Marine Genomics Europe". CS wishes to acknowledge additional funding from the Ministry of Education and Science (Spain) through grant AGL2007-60049. MM had a PhD scholarship from the University of Florence, Italy. RL was recipient of PhD fellowship SFRH/BD/30112/2006, from the Portuguese Science and Technology Foundation (FCT) and LC and RL acknowledge a grant from FCT project ISOPERK (PTDC/CVT/72083/2006). We thank also two anonymous reviewers for their useful comments on an earlier version of the manuscript.

\section{Author details}

'Department of Public Health, Comparative Pathology, and Veterinary Hygiene, Faculty of Veterinary Medicine, University of Padova, Viale dell'Università 16, 35020 Legnaro, Italy. ${ }^{2}$ Department of Evolutionary Biology, University of Florence, 50125 Florence, Italy. ${ }^{3}$ Biology Department, University of Padova, Via G. Colombo 3, I-35131 Padova, Italy. ${ }^{4}$ Max Planck Institute for Molecular Genetics, Ihnestraße 63-73, 14195 Berlin, Germany. ${ }^{5}$ CCMAR/
University of Algarve, Campus de Gambelas, Faro, Portugal. ${ }^{6}$ Instituto de Acuicultura de Torre la Sal (IATS), Consejo Superior de Investigaciones Cientificas (CSIC), 12595 Ribera de Cabanes, Castellon, Spain.

\section{Authors' contributions}

$L B, M M, C C, T M, G C, R L, L C$ and CS conceived and designed the project. RR produced the EST sequences. SB and AC conceived and constructed the database. MM carried out probe design and editing, and performed microarray experiments. MM and LB executed all statistical analyses. MM performed functional annotation analyses. LB and MM wrote the manuscript. All listed authors edited the manuscript. All authors read and approved the manuscript.

Received: 19 November 2010 Accepted: 12 May 2011

Published: 12 May 2011

\section{References}

1. FAO:[http://www.fao.org/fishery/culturedspecies/Ruditapes_philippinarum/ en].

2. Saavedra C, Bachère E: Bivalve genomics. Aquaculture 2006, 256:1-14.

3. Yasuda N, Nagai S, Yamaguchi S, Lian CL, Hamaguchi M: Development of microsatellite markers for the Manila clam Ruditapes philippinarum. Mol Ecol Notes 2007, 7:43-45.

4. Fleury E, Moal J, Boulo V, Daniel JY, Mazurais D, Hénaut A, Corporeau C, Boudry P, Favrel P, Huvet A: Microarray-Based Identification of Gonad Transcripts Differentially Expressed Between Lines of Pacific Oyster Selected to Be Resistant or Susceptible to Summer Mortality. Mar Biotechnol (NY) 2010, 12:326-39.

5. Leaver MJ, Diab A, Boukouvala E, Williams TD, Chipman JK, Moffat CF, Robinson CD, George SG: Hepatic gene expression in flounder chronically exposed to multiply polluted estuarine sediment: Absence of classical exposure 'biomarker' signals and induction of inflammatory, innate immune and apoptotic pathways. Aquat Toxicol 2009, 96:234-245.

6. Falciani F, Diab AM, Sabine V, Williams TD, Ortega F, George SG, Chipman JK: Hepatic transcriptomic profiles of European flounder (Platichthys flesus) from field sites and computational approaches to predict site from stress gene responses following exposure to model toxicants. Aquat Toxicol 2008, 90:92-101

7. Van Aggelen G, Ankley GT, Baldwin WS, Bearden DW, Benson WH, Chipman JK, Collette TW, Craft JA, Denslow ND, Embry MR, Falciani F, George SG, Helbing CC, Hoekstra PF, Iguchi T, Kagami Y, Katsiadaki I, Kille P, Liu L, Lord PG, Mclntyre T, O'Neill A, Osachoff H, Perkins EJ, Santos EM, Skirrow RC, Snape JR, Tyler CR, Versteeg D, Viant MR, Volz DC, Williams TD, Yu L: Integrating omic technologies into aquatic ecological risk assessment and environmental monitoring: hurdles, achievements, and future outlook. Environ Health Perspect 2010, 118:1-5.

8. Moschino V, Delaney E, Meneghetti F, Ros LD: Biomonitoring approach with mussel Mytilus galloprovincialis (Lmk) and clam Ruditapes philippinarum (Adams and Reeve, 1850) in the Lagoon of Venice. Environ Monit Assess 2010.

9. Matozzo V, Binelli A, Parolini M, Locatello L, Marin MG: Biomarker responses and contamination levels in the clam Ruditapes philippinarum for biomonitoring the Lagoon of Venice (Italy). J Environ Monit 2010, 12:776-86.

10. Millán A, Gómez-Tato A, Fernández C, Pardo GB, Álvarez-Dios JA, Calaza M, Bouza C, Vázquez M, Cabaleiro S, Martínez P: Design and Performance of a Turbot (Scophthalmus maximus) Oligo-microarray Based on ESTs from Immune Tissues. Mar Biotechnol 2009, 12:452-465.

11. Ferraresso $S$, Milan $M$, Pellizzari $C$, Vitulo N, Reinhardt $R$, Canario AV, Patarnello T, Bargelloni L: Development of an oligo DNA microarray for the European sea bass and its application to expression profiling of jaw deformity. BMC Genomics 2010, 3(11):354

12. Salem M, Kenney PB, Rexroad CE III, Yao J: Development of a 37 k highdensity oligonucleotide microarray: a new tool for functional genome research in rainbow trout. J Fish Biol 2008, 72:2187-2206.

13. Kane MD, Sringer JA, lannotti NV, Gough E, Johns SM, Schlueter SD, Sepulveda MS: Identification of development and tissue-specific gene expression in the fathead minnow Pimephales promelas, Rafinesque using computational and DNA microarray methods. J Fish Biol 2008 , 72:2341-2353. 
14. Villeneuve DL, Knoebl I, Larkin P, Miracle AL, Carter BJ, Denslow ND, Ankley GT: Altered gene expression in the brain and liver of female fathead minnows Pimephales promelas Rafinesque exposed to fadrozole. J Fish Biol 2008, 72:2281-2340.

15. Klaper R, Carter BJ, Richter CA, Drevnick PE, Sandheinrich MB, Tillitt DE: Use of a $15 \mathrm{k}$ gene microarray to determine gene expression changes in response to acute and chronic methylmercury exposure in the fathead minnow Pimephales promelas Rafinesque. J Fish Biol 2008, 72:2207-2280.

16. Li T, Brouwer M: Gene expression profile of grass shrimp Palaemonetes pugio exposed to chronic hypoxia. Comp Biochem Physiol Part D Genomics Proteomics 2009, 4:196-208.

17. Ramsey JS, Wilson AC, de Vos M, Sun Q, Tamborindeguy C, Winfield A, Malloch G, Smith DM, Fenton B, Gray SM, Jander G: Genomic resources for Myzus persicae: EST sequencing, SNP identification, and microarray design. BMC Genomics 2007, 8:423.

18. Ferraresso S, Vitulo N, Mininni AN, Romualdi C, Cardazzo B, Negrisolo E, Reinhardt R, Canario AV, Patarnello T, Bargelloni L: Development and validation of a gene expression oligo microarray for the gilthead sea bream (Sparus aurata). BMC Genomics 2008, 9:580.

19. Craft JA, Gilbert JA, Temperton B, Dempsey KE, Ashelford K, Tiwari B, Hutchinson TH, Chipman JK: Pyrosequencing of Mytilus galloprovincialis CDNAs: tissue-specific expression patterns. PLoS One 2010, 25(5):8875.

20. Bettencourt R, Pinheiro M, Egas C, Gomes P, Afonso M, Shank T, Santos RS: High-throughput sequencing and analysis of the gill tissue transcriptome from the deep-sea hydrothermal vent mussel Bathymodiolus azoricus. BMC Genomics 2010, 11:559.

21. RuphiBase. [http://compgen.bio.unipd.it/ruphibase/]

22. GEO data base. [http://www.ncbi.nlm.nih.gov/geo/].

23. DAVID. [http://david.abcc.ncifcrf.gov/]

24. Forrest $A R$, Carninci P: Whole genome transcriptome analysis. RNA Biol 2009, 6:107-12

25. Kapranov P, Willingham AT, Gingeras TR: Genome-wide transcription and the implications for genomic organization. Nat Rev Genet 2007, 8:413-23.

26. Carninci P: RNA dust: where are the genes? DNA Res 2010, 17:51-9.

27. Ponting $C P$, Grant Belgard T: Transcribed dark matter: meaning or myth? Hum Mol Genet 2010, 19:162-168.

28. Zhang Y, Liu XS, Liu QR, Wei L: Genome-wide in silico identification and analysis of cis natural antisense transcripts (cis-NATs) in ten species. Nucleic Acids Res 2006, 34:3465-3475.

29. Lapidot M, Pilpel Y: Genome-wide natural antisense transcription: coupling its regulation to its different regulatory mechanisms. EMBO Rep 2006, 7:1216-1222.

30. Werner A, Sayer JA: Naturally occurring antisense RNA: function and mechanisms of action. Curr Opin Nephrol Hypertens 2009, 18:343-349.

31. Galloway TS: Biomarkers in environmental and human health risk assessment. Mar Pollut Bull 2006, 53:606-13.

32. Losso C, Ghirardini AV: Overview of ecotoxicological studies performed in the Venice Lagoon (Italy). Environ Int 2010, 36:92-121.

33. Moore MN, Allen Jl, McVeigh A, Shaw J: Lysosomal and autophagic reactions as predictive indicators of environmental impact in aquatic animals. Autophagy 2006, 2:217-20.

34. Sancak Y, Bar-Peled L, Zoncu R, Markhard AL, Nada S, Sabatini DM: Ragulator-Rag complex targets mTORC1 to the lysosomal surface and is necessary for its activation by amino acids. Cell 2010, 141:290-303.

35. Nakatsu Y, Kotake Y, Takai N, Ohta S: Involvement of autophagy via mammalian target of rapamycin (mTOR) inhibition in tributyltin-induced neuronal cell death. J Toxicol Sci 2010, 35:245-51.

36. Blanchette B, Feng X, Singh BR: Marine glutathione S-transferases. Mar Biotechnol (NY) 2007, 9:513-42.

37. Huse SM, Huber JA, Morrison HG, Sogin ML, Welch DM: Accuracy and quality of massively parallel DNA pyrosequencing. Genome Biol 2007, 8:143

38. Konishi T, Kato K, Araki T, Shiraki K, Takagi M, Tamaru Y: A new class of glutathione S-transferase from the hepatopancreas of the red sea bream Pagrus major. Biochem J 2005, 388:299-307.

39. Whalen KE, Morin D, Lin CY, Tjeerdema RS, Goldstone JV, Hahn ME: Proteomic identification, CDNA cloning and enzymatic activity of glutathione S-transferases from the generalist marine gastropod Cyphoma gibbosum. Arch Biochem Biophys 2008, 478:7-17.
40. Micheletti C, Critto A, Marcomini A: Assessment of ecological risk from bioaccumulation of PCDD/Fs and dioxin-like PCBs in a coastal lagoon. Environment International 2007, 33:45-55.

41. Passamonti M, Mantovani B, Scali V: Allozymic characterization and genetic relationships among four species of Tapetinae (Bivalvia Veneridae). Italian Journal of Zoology 1997, 64:117-124.

42. Irato P, Santovito G, Cassini A, Piccinni E, Albergoni V: Metal Accumulation and Binding Protein Induction in Mytilus galloprovincialis, Scapharca inaequivalvis, and Tapes philippinarum from the Lagoon of Venice. Arch Environ Contam Toxicol 2003, 44:476-484.

43. Moschino V, Delaney E, Meneghetti F, Ros LD: Biomonitoring approach with mussel Mytilus galloprovincialis (Lmk) and clam Ruditapes philippinarum (Adams and Reeve, 1850) in the Lagoon of Venice. Environ Monit Assess 2010

44. Bellucci LG, Frignani M, Paolucci D, Ravanelli M: Distribution of heavy metals in sediments of the Venice Lagoon: The role of the industrial area. Science of the Total Environment 2002, 295:35-49.

45. Bernardello M, Secco T, Pellizzato F, Chinellato M, Sfriso A, Pavoni B: The changing state of contamination in the Lagoon of Venice. Part 2: Heavy metals. Chemosphere 2006, 64:1334-1345.

46. Gaworecki KM, Rice CD, van den Hurk P: Induction of phenol-type sulfotransferase and glucuronosyltransferase in channel catfish and mummichog. Mar Environ Res 2004, 58:525-528.

47. Lie KK, Lanzen A, Breilid H, Olsvik PA: Gene expression profiling in Atlantic cod (Gadus morhua L.) from two contaminated sites using a custommade cDNA microarray. Environ Toxicol Chem 2009, 28:1711-21.

48. Gamage N, Barnett A, Hempel N, Duggleby RG, Windmill KF, Martin JL, McManus ME: Human sulfotransferases and their role in chemical metabolism. Toxicol Sci 2006, 90:5-22.

49. Somnuek C, Boonphakdee C, Cheevaporn V, Tanaka K: Gene expression of acetylcholinesterase in hybrid catfish (Clarias gariepinus X Clarias macrocephalus) exposed to chlorpyrifos and carbaryl. J Environ Biol 2009, 30:83-8.

50. Boutet I, Tanguy A, Moraga D: Characterisation and expression of four mRNA sequences encoding glutathione S-transferases pi, mu, omega and sigma classes in the Pacific oyster Crassostrea gigas exposed to hydrocarbons and pesticides. Marine Biology 2004, 146:53-64.

51. Xu C, Pan L, Liu N, Wang L, Miao J: Cloning, characterization and tissue distribution of a pi-class glutathione S-transferase from clam (Venerupis philippinarum): Response to benzo[alpha]pyrene exposure. Comp Biochem Physiol C Toxicol Pharmacol 2010, 152:160-166.

52. Falfushynska HI, Gnatyshyna LL, Golubev AP, Stoliar OB: Main partitioning criteria for the characterization of the health status in the freshwater mussel Anodonta cygnea from spontaneously polluted area in western ukraine. Environ Toxicol 2010

53. Bourgeault A, Gourlay-Francé C, Vincent-Hubert F, Palais F, Geffard A, Biagianti-Risbourg S, Pain-Devin S, Tusseau-Vuillemin MH: Lessons from a transplantation of zebra mussels into a small urban river: An integrated ecotoxicological assessment. Environ Toxicol 2010, 25:468-78.

54. Vera JC, Wheat CW, Fescemyer HW, Frilander MJ, Crawford DL, Hanski I, Marden JH: Rapid transcriptome characterization for a nonmodel organism using 454 pyrosequencing. Mol Ecol 2008, 17:1636-47.

55. Maiuri MC, Zalckvar E, Kimchi A, Kroemer G: Self-eating and self-killing: crosstalk between autophagy and apoptosis. Nat Rev Mol Cell Biol 2007, 8:741-52.

56. Fabioux C, Corporeau C, Quillien V, Favrel $P$, Huvet A: In vivo RNA interference in oyster-vasa silencing inhibits germ cell development. FEBS J 2009, 276:2566-73.

57. Chomczynski P, Sacchi : Single step method of RNA isolation by acid guanidinium thiocyanate-phenol-chloroform extraction. Anal Biochem 1987, 162:156-159.

58. Kozhemyako VB, Matz MV, Meleshkevitch E, Moroz LL, Lukyanov SA, Shagin DA: Simple cDNA normalization using kamchatka crab 694 duplex-specific nuclease. Nucleic Acids Res 2004, 32:e37.

59. Margulies M, Egholm M, Altman WE, Attiya S, Bader JS, Bemben LA, et al: Genome sequencing in microfabricated high-density picolitre reactors. Nature 2005, 437:376-380.

60. Chevreux B, Pfisterer T, Drescher B, et al: Using the miraEST assembler for reliable and automated mRNA transcript assembly and SNP detection in sequenced ESTs. Genome Res 2004, 14:1147-59. 
61. UniProt. [http://www.ebi.ac.uk/uniprot/]

62. Ensembl Genome Browser. [http://www.ensembl.org/index.html].

63. Lottia gigantea v1.0 database. [http://genome.jgi-psf.org/Lotgi1/Lotgi1. download.ftp.html].

64. NCBI UniGene database. [http://www.ncbi.nlm.nih.gov/unigene].

65. Sigenae. [http://www.sigenae.org/].

66. Bay scallop EST project. [http://www.mbl.edu/aquaculture/EST/].

67. Götz S, García-Gómez JM, Terol J, Williams TD, Nagaraj SH, Nueda MJ, Robles M, Talón M, Dopazo J, Conesa A: High-throughput functional annotation and data mining with the Blast2GO suite. Nucleic Acids Res 2008, 36:3420-35.

68. Geneontology. [http://www.geneontology.org/GO.slims.shtml].

69. Hu ZL, Bao J, Reecy JM: CateGOrizer: A web-based program to batch analyze gene ontology classification categories. Online J Bioinform 2008, 9:108-112.

70. Agilent eArray. [https://earray.chem.agilent.com/earray/].

71. R statistical software. [http://www.r-project.org].

72. Thusher V, Tibshirani R, Chu G: Significance analysis of microarrays applied to the ionizing radiation response. Proc Natl Acad Sci USA 2001, 98:5116-5121.

73. Ensembl BioMart. [http://www.ensembl.org/biomart/martview/]

74. Notredame C, Higgins D, Heringa J: T-Coffee: A novel method for multiple sequence alignments. Journal of Molecular Biology 2000, 302:205-217.

75. Castresana J: Selection of conserved blocks from multiple alignments for their use in phylogenetic analysis. Molecular Biology and Evolution 2000, 17:540-552.

76. Felsenstein J: Inferring Phylogenies. Sinauer, Sunderland, MA. Syst Biol 2004, 53:669-670.

77. Guindon S, Gascuel O: A simple, fast, and accurate algorithm to estimate large phylogenies by maximum likelihood. Syst Biol 2003, 52:696-704.

doi:10.1186/1471-2164-12-234

Cite this article as: Milan et al:: Transcriptome sequencing and microarray development for the Manila clam, Ruditapes philippinarum: genomic tools for environmental monitoring. BMC Genomics 2011 12:234

\section{Submit your next manuscript to BioMed Central} and take full advantage of:

- Convenient online submission

- Thorough peer review

- No space constraints or color figure charges

- Immediate publication on acceptance

- Inclusion in PubMed, CAS, Scopus and Google Scholar

- Research which is freely available for redistribution

Submit your manuscript at www.biomedcentral.com/submit 